\title{
Strategies of Teaching Writing at Saudi Tertiary-Level Institutions: Reality and Expectations
}

\author{
Khaled Abkar Alkodimi \\ Department of English Language and Literature \\ College of Languages and Translation \\ Imam Mohammad Ibn Saud Islamic University, Saudi Arabia \\ Corresponding Author:kaq2002@yahoo.com \\ Arif Ahmed Mohammed Hassan Al-Ahdal \\ Department of English Language \\ College of Arts and Sciences \\ Methnab, Qassim University, Saudi Arabia
}

Received: 2/1/2021

Accepted: 6/8/2021

Published: 6/24/2021

\begin{abstract}
Teaching writing in English is a particularly daunting task for EFL teachers. Much of it concerns teaching accuracy in text production, development and thought expression which is usually not the teachers' stated aim. Thus, teachers' perceptions to the teaching of writing and the actual classroom practices need examination, which is the aim of this study, a prerequisite to recommending pedagogical changes to bridge the gap that exists between educational aims and outcomes so far as the teaching of writing to EFL learners in Saudi tertiary level educational institutions is concerned. The study applies a quantitative approach via a survey conducted with one hundred EFL teachers at Imam Mohammed Ibn Saud Islamic University (IMBSIU, henceforth), Qassim University and King Khaled University, Saudi Arabia. Results suggest that inadequate English resources and inefficient teaching methods are, in general, the main causes of poor writing skills. Further, the teachers perceive limited lexis, irregular sentences, and orthographical differences with the mother tongue as impediments in the learners' ability to write well in English. The study concludes with some pertinent recommendations to remedy the situation.
\end{abstract}

Keywords: EFL teachers, learners, perceptions, strategies, tertiary, writing

Cite as: Alkodimi, K. A., \& Al-Ahdal, A.A.M.H. (2021). Strategies of Teaching Writing at Saudi Tertiary-Level Institutions: Reality and Expectations. Arab World English Journal, 12 (2) 399- 413. DOI: https://dx.doi.org/10.24093/awej/vol12no2.27 


\section{Introduction}

Writing, due to various intrinsic attributes and extrinsic factors, seems to be the most challenging skill for language learners, both as the first and/or as the second or foreign language, relative to other main skills of listening, reading and speaking (Keller, Fleckenstein, Krüger, Köller, \& Rupp. 2020; Thomas, 2020). It is often a solitary, burdensome undertaking, usually given as homework and therefore unsupported, leaving one to their own devices. There is a lot of research specifically on the problems of writing in EFL, but in practice, students still 'dread' writing and compositional tasks. Writing, however, is a fundamental and practical skill that, among others, enables one to be more than the passive recipient of linguistic input, more importantly, fosters critical thinking abilities. While writing, students have the opportunity to express and evaluate their thoughts and feelings, whether consciously or unconsciously. With young EFL learners, it becomes doubly challenging since they are both learning a language and, at the same time, their opinions and worldviews are largely unformed, and the process of creating well-thought units and structures in a foreign language efficiently appears an arduous task in the eyes of young learners. Writing is essentially a visual and imaginative enterprise represented by, and atomized in, words. It uses symbols to reflect speech patterns, including signs as punctuation and numerals, and defines the language units in action.

In their article on writing for learners of the first and/or second language, Raimes (1983) sees writing as the skill that comes with the most baggage, among other things, of fright, disinterest, anguish, and nail-biting. Though it may come as a surprise to teachers of different subjects that writing should be such a big challenge for the learner of English, the fact of the matter is that it is no less challenging even for native speakers of languages. Reasons are many, and complex too, but what makes writing a particularly difficult and uninteresting task is the hackney-ism that might be seeped into the process, low innovation, and the difference in space and time of the communication that the written word is intended to achieve (Al-Ahdal, 2020a; 2020b).

Compared to speaking, writing discounts the message that is partly conveyed by expressions, tone, intonation and pitch, body language, eye contact, and above all, the instant feedback offered by spontaneous dialog. The writer is removed from his/her readers, unable to predict who the readers will be and what kind of preconceived notions and knowledge they will encounter when reading the text created by them. Therefore, writing requires an effort to think and organise ideas in a more logical sequence and better proficiency in the language and grammatical rules. It also requires adequate vocabulary bank, knowledge and awareness of syntax and morphology and all the wherewithal of linguistic ability that aids communication, including the very powerful and ever-present challenge of L1 (first language) interference.

The question of teaching writing and EFL teachers' perceptions of it has long been a matter of debate and controversy in the EFL community. Too often, teachers would rather put off, if not entirely do away with, the activity under the pretence that it is 'too difficult to teach' and that it is enough if learners pick up whatever they can in writing along the way as they move on (Al-Ahdal \& Al-Mashaqba, 2016). They are generally unsympathetic to, and condescendingly dismissive of, learners' poor textual output, deeming it good enough as it is, and are outright averse to finding why learners find it difficult to write in English. During informal interviews to test the hypothesis, it was informative to find that in EFL teachers' perceptions, the smallest unit 
of writing was considered to be the sentence. In other words, when they undertake teaching writing, they ask learners to focus on the grammatical correctness of the sentence. Though 'correct' production of text is indeed one of the aims of teaching writing, emphasizing only that aspect of the task results in the accuracy rather than the expression of the desired outcome. Writing as a process involves certain stages not precisely understood by these teachers, including but not limited to, the accuracy of expression with the text being organised as a coherent discourse based on logical sequencing of ideas for the writing of disjointed and unconnected sentences in the hope of improving the learners' writing skills. This paper examines the existing gap between the objectives of teaching writing, teachers' perceptions of teaching writing, and the actual pedagogical practices undertaken to accomplish the task.

Teaching English involves four core skills, speaking, listening, reading and writing. Writing, for various reasons, has come to be the most challenging skill for both, students to learn, and teachers to impart (Abedi, Namaziandost, \& Akbari, 2019; Kardena, Syarif, \& Zaim, 2020; Sukmawati \& Nasution, 2020). It is an integrated communicative competency that requires intelligent and purposive allocation of time and resources. Compared to speaking, writing requires more rigorous planning and organization because it is by nature deprived of the advantages of the intuitive and spontaneous nature of speech production offers, such as the use of fillers, pauses and gestures. Unlike the interlocutor, the writer is expected to be more logical and to-the-point since the reader enters the writer's world expecting equally organized and to-thepoint content. In terms of motivation, it is interesting to know that many students 'dread' writing to the point that they even refuse to physically participate in composition classes, with writing seminars having the highest number of absentees. With English as a foreign language (EFL), the issue becomes even more severe, where the language taught is seldom offered outside the classroom environment. According to the theory of contemplated conduct, students' discernments and perceptions of a subject relate directly to their academic success and/or failure. The influence of learner cognition and perceptions of their classroom writing sessions is also a determining factor.

Writing proficiency is not only desired but also required because of its importance to students' future academic and professional success (Bracewell, 2020; Seçer \& Yücel-Toy, 2020; Zahroh, Mujiyanto \& Saleh, 2020; Surya, et al., 2020). Communicating efficiently is the cornerstone of any occupation regardless of how unrelated writing may seem to a specific field, it is important to consider writing as an essential component of one's skillset. Although most modern-day workplaces have become more 'casual' in terms of communication, it is still important to maintain professionalism in email correspondences or other written exchanges. Texts 'battered' by incorrect grammar or typos may undermine one's professionalism and attention to detail. According to Darmawangsa, Mutiarsih, Karimah, \& Racmadhany (2020), academic writing encompasses an interpretation of distinctive concepts and experiences focused on the specific or general skills of writing. Writing requires, and at the same time encourages, inventiveness, innovation and clear mutual comprehension. It is a cognitive activity requiring a brain process that involves visualization and imagination in order to form concepts and ideas. Therefore, it is essential to develop students' writing skills from early levels as they are important communication skills in this globalized, interconnected world. Because of its importance, most countries, including Saudi Arabia, have made the English language mandatory 
in education. In the Kingdom of Saudi Arabia, students study English from preschool to varsity level.

This study proposes to fulfil two objectives: To investigate teachers' perceptions of teaching writing at Saudi tertiary level educational institutions, and to propose practical pedagogical measures for improving students' writing skills in these institutions. Based on these objectives, this study intends to answer the following questions:

1. What are the perceptions of the EFL teachers at Saudi tertiary level institutions of the teaching of writing?

2. What are the perceived and actual obstacles to achieving the objectives of teaching writing in these institutions?

3. Is it possible to realize the objectives of teaching writing by introducing pedagogical changes to the educational system?

\section{Research Problem}

Writing is an essential linguistic and communicative skill for EFL learners in Saudi tertiary level institutions as they need to be able to write adequately in the language for their present and future educational and professional success. They come to these institutions in the hope of attaining a certain level of communicative competence that would empower them to develop and exchange information, ideas, and particular or general arguments. First and foremost, it is EFL teachers' responsibility to help them fulfil their communicative potential in writing. However, these learners have been observed not to be adequately competent writers at the end of their institution term. This study aims to investigate the reasons for this institutional mishap and to suggest ways to address learners' needs. Mastery of structure and complex linguistic components such as syntax, terminology, expressions and phrases, and psychological and emotional restraints are deterrent factors. This study focuses primarily on addressing these issues and attempts to find answers that lead to practical procedures and processes.

\section{Significance of the Study and Research Context}

Writing is a form of exchanging concepts, opinions and feelings. Writing in ESL and EFL also has the added advantage of offering students an opportunity to both learn a language and to be able to convey thoughts, emotions and viewpoints freshly and differently from one's mother tongue. The present research is significant because it informs a wide range of professionals involved in research on writing for academic and/or professional needs. It will also help realise the ambitious yet achievable objectives of Saudi Arabia's Vision 2030, particularly, its stated aim of creating a vibrant, informed and forward-looking society with qualified graduates. Our younger generation's ability to be able to communicate with the global community using English, as the international lingua franca, is thus a given in this direction, as it has permeated every field, whether academic, economic, political or social. We need to empower our people to interact with the outside world efficiently and collaboratively.

One reason for students' inability to write is that they have not been taught to start the writing process (Al-Ahdal, Alfallaj, Al-Awaied, \& Al-Hattami, 2014; Alfallaj \& Al-Ahdal, 2017; Magulod, 2018), which is, in turn, due to problems such as the fact that there has historically been little demand and 'push' from the teachers for creativity and innovation in writing classes. This has led to confusion, frustration and inability to write down the very first sentence, metaphorically speaking, as they are unaccustomed to forming outlines and well-structured 
thought processes epitomized in, and essential to the act of writing. The seemingly simple question of the starting point of writing is a great challenge before the Saudi Arabian student and it is common for teachers to hear them complain in words such as "I do have a lot in my mind, I would like to write down, but I don't know where to start", and "I overthink and constantly change my mind about the topic I want to write and feel crippled and alone in this". Writing is, therefore, an essential skill for Saudi Arabian students in that they learn to use the proper structure for the optimal conveyance of ideas logically and reliably.

\section{Literature Review}

Numerous studies have been done on the role of teacher/learner perceptions and teaching English as a second or foreign language. In his analysis of English teachers' perceptions in East Java and Indonesia, Hidayati (2018) concluded that there were two types of factors that posed a challenge before the teachers. The first were internal factors, including language competence, mother tongue interference and poor learner motivation and their reading habits. The second type were the external factors such as infrastructural realities and limitations and pressure from institutional authorities. According to Butler, Trosclair, Zhou and Wei (2014), assessing teacher/learner perceptions in second language learning is important as conflicting perceptions can lead to a failure in achieving learning objectives. Ferede, Melese, and Tefera (2012) examined the perceptions of teaching English writing and the actual teaching practices of teachers in Ethiopia. Their findings showed that due to teachers' flawed and misplaced perceptions, their teaching practice was equally flawed and did not bear the intended results. In a similar study of English teachers' perceptions of teaching writing, Fu and Matoush (2011) found the problem to be too much emphasis on rather 'linguistically controlled language instruction' than ensuring proficiency as a communication tool. Skills orientation was also almost exclusively test-driven and teacher preparation was minimal. Students' speaking skills can further benefit from practicing writing since it offers an opportunity to learn 'rarer' vocabulary, syntax and structures, punctuation and, in general, language. Also, though writing skills are important for interpersonal communication, they are just as important externally, if not more so, for online publication which is the aim of most academics. The content that is difficult to understand, poorly written, or has spelling or grammatical errors can hardly be published, no matter how informative and rich the content may be.

\section{Theories of Teaching Writing}

Theories of teaching writing are essential in that they equip teachers with ideas that result in better and more intelligent practice. In his theorization of the process of teaching writing, Hodges (2017) outlined four key areas:

\section{The Cognitive Process Theory of Writing}

Writing is a thinking process involving mental mechanisms such as brainstorming, preparation and organizing. The cognitive writing theory and the methodology it presents, help students learn how to use conceptual thinking and integrate it into their writing process. The hypothesis was further developed by Flower and Hayes (1981) by taking into account student feedback, leading to the incorporation of the theory of cognitive processes into literary prose composition. The theory holds that since writers experience a thought phase before writing, it is important to establish macro- and micro-goals and a more inclusive hierarchical framework, and to set specific and clear objectives to achieve the goal(s) of writing. 


\section{The Sociocultural Theory of Writing}

The sociocultural theory of writing was formulated by the Soviet psychologist Lev Semyonovich Vygotsky. His theory views a thinking agent's development as a socially mediated process in which they acquire their cultural values, beliefs, and problem-solving strategies through collaborative dialogues with more knowledgeable members of society. Vygotsky's theory is comprised of concepts such as culture-specific tools, private speech, and the Zone of Proximal Development. In short, it emphasizes the role of inspiration, effect and social forces as the main components of writing. Another significant aspect of his theory is the recognition of the role of socialization and engagement in the production of mental behavior or information retention phase. According to the theory of Zone of Proximal Development, students need assistance and socialization, in the form of collaboration with their teachers and peers, to improve and acquire the language in its fullness as a social concept (Vygotsky, 1978).

\section{Social Cognitive Theory and Self-efficacy in Writing}

The social cognitive theory relates to the interaction between cognitive, physiological, personal and environmental variables to assess motivation and actions (Bandura, 1993). It focuses on the three major components of observational learning, imitation and simulation. In the pedagogical context, its effectiveness and success rely on the teacher's ability to help students carry on with the written task and overcome obstacles as they transpire. It would further aid them to select professions where they have strong self-efficacy and avoid tasks with poor performance (Bandura, 2001). Self-observation, self-evaluation, self-reaction and self-efficacy are its four principal objectives to be met in order for students' full potential to be realized.

\section{Ecological Theory}

According to the ecological theory of writing, students collaborate in the class to build structures within which the learner and the written product both control and are controlled by the scripts of other students in the environment. A writing ecology requires more than the individual writer and their immediate background. One of the critical aspects of this theory is that the attributes of a particular writer or writers are both described and dictated by other writers' attributes. Another significant aspect of the ecological process is its inherent versatility, which means although frameworks and contents may be described relative to a specific period, they constantly change in actual periods. This principle is restricted to shifting over longer times. In a study using the Reading to Learn strategy in teaching academic writing to Indonesian tertiary level EFL learners, Listyani (2018) gathered some useful results. First, Reading to Learn is effective to teach Academic Writing. Secondly, not all tertiary students like working cooperatively. Some prefer working individually. The next conclusion is students perceive peer review as an important part of their essay writing.

\section{Teaching Writing}

Teaching writing involves the employment, and impartation, of different techniques and strategies to learners to make them become, ideally, autonomous writers in their own right (Kim \& Kang, 2020; Lee, 2020; Timizar-Le Pen, Marchand, Léocadie, \& Rothan-Tondeur, 2020). It includes a wide array of approaches that attempt to bridge the gap between beliefs about writing with methods employed by writers that in turn affect the production of writing outcomes. In this way, the written text is embodied by the concepts, rules, and ethics relevant to the writing method that were implemented, especially in teaching classrooms. Since writing methods are 
essential to any lesson planning in writing, the techniques employed should be able to realistically arrive at the intended outcomes. In other words, to see a successful impact in students' writing output, it is important to set the right strategies. Otherwise, the tasks will be overwhelming and demoralizing for both students and teachers, as they see no return for their hard work. An example of setting effective strategies would be to introduce the minimal experience to a product-centered method to beginners, as templates or examples are required to begin their journey via writing. A writing classroom without a set aim, approach and methodology, is doomed to trial and error with great, irreversible loss of valuable time and resources to learners and educators.

\section{Methods}

The current study is quantitative in nature and it employs a detailed questionnaire developed by Hedge (1988) to assess teachers' approach to teaching of writing. It may be added that some items were modified merely to accommodate the Saudi context, though without changing the factor loading of the questions. This was administered to one hundred EFL teachers from three Saudi Arabian tertiary-level educational institutions of Imam Mohammad Ibn Saud University, Qassim University and King Khalid University. They were selected randomly to ensure the reliability of generalizations of the findings. The responses to the questionnaire were stacked into a writing matrix with the format presented below, as a guide to the respondents as to what to follow on writing challenges:

\section{Types of writing \\ 2. Difficulties in writing \\ 3. Improving drafts \\ 4. Collaboration}

These categories were selected since the researcher's personal teaching experience spanning more than a decade had led to the formation of these categories as being significant so far as EFL writing was concerned. Relevant recommendations based on inferences from the above categories will be presented in the conclusion and implications section of the study.

\section{Results and Discussion}

The study shows that Saudi students, as expressed by the participants/teachers, consider writing 'summaries' (4.25) the most important written task and writing 'topic expressions and supporting material' (4.08) as second in importance. Less than one standard deviation suggests that participants did not display significant variation in their answers to these two factors.

Table 1. Tasks perceived as significant by teachers

\begin{tabular}{|l|c|c|c|}
\hline \multicolumn{1}{|c|}{ Tasks } & Mean & SD & Rank \\
\hline Topic sentences and supporting details & 4.08 & 0.43 & 2 \\
\hline Paragraph writing & 3.86 & 0.10 & 3 \\
\hline Summaries & 4.25 & 0.99 & 1 \\
\hline Letter writing & 3.34 & 1.66 & 7 \\
\hline Narrative essays & 3.01 & 1.73 & 8 \\
\hline Descriptive essays & 3.38 & 1.20 & 6 \\
\hline Argumentative essays & 3.45 & 1.75 & 4 \\
\hline Expository essays & 3.42 & 1.91 & 5 \\
\hline
\end{tabular}




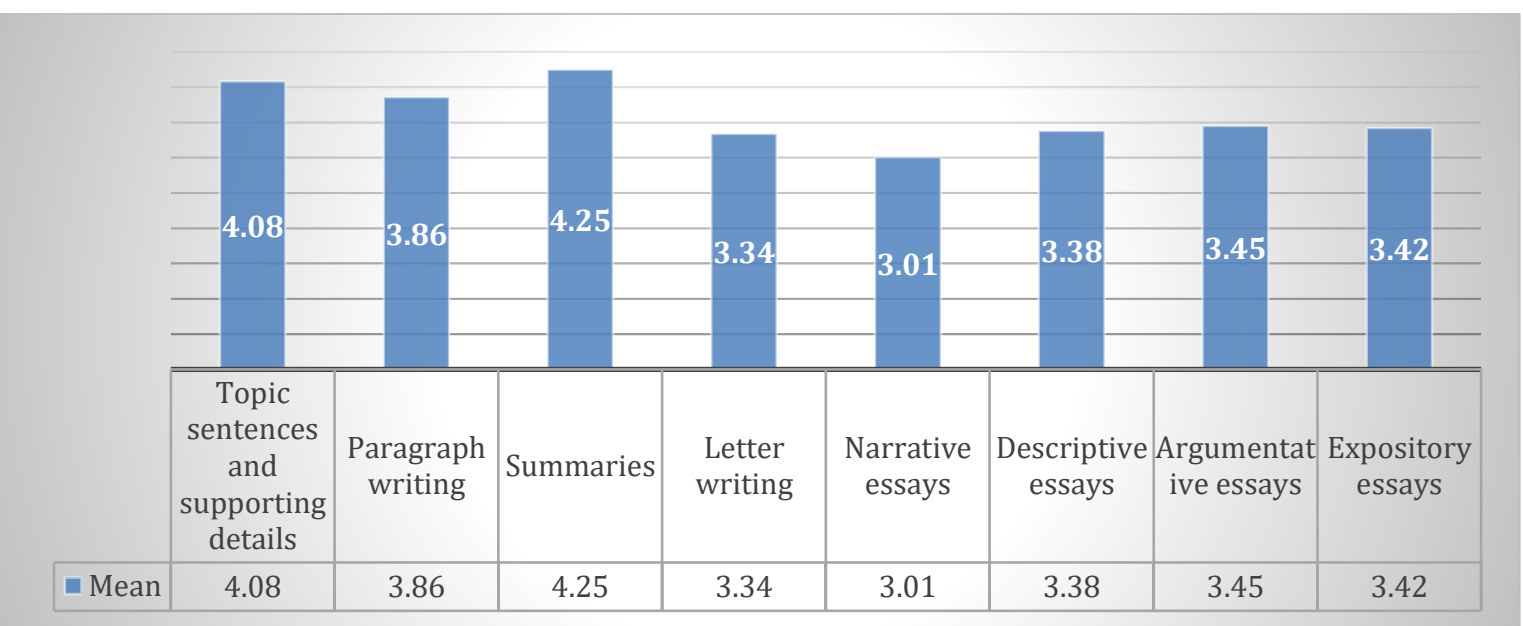

Figure 1. Tasks perceived as significant by teachers

Numerous studies have shown that Saudi Arabian students have serious problems in their essential writing skills (El Tantawi, Sadaf, \& AlHumaid, 2018; Imsa-ard, 2020; Zemni \& Alrefaee, 2020; McMaster, et al, 2019; Go Silk, et al, 2020; Oppenheimer, et al, 2017; Rakedzon \& Baram-Tsabari, 2017). Participants, in these and other studies, have been observed to comparatively assign lesser rates of value to the factors important to writing different types of essays. It can be inferred that in general, participants do not consider writing classes helpful in their writing since they are not even able to reach paragraph-level competency in writing.

Table 2. Problems faced in academic writing tasks as perceived by teachers

\begin{tabular}{cccc}
\hline Item & mean & SD & Rank \\
\hline Appropriate vocabulary & 3.80 & 1.05 & 1 \\
\hline Spellings & 3.26 & 1.09 & 5 \\
\hline Use of articles & 3.18 & 1.07 & 7 \\
\hline Punctuation & 3.14 & 1.11 & 4 \\
\hline Use of prepositions & 3.30 & 1.09 & 3 \\
\hline Use of irregular verbs & 3.45 & 1.14 & 8 \\
\hline Use of question words & 3.09 & 1.04 & 2 \\
\hline Grammar & 3.60 & 1.17 &
\end{tabular}

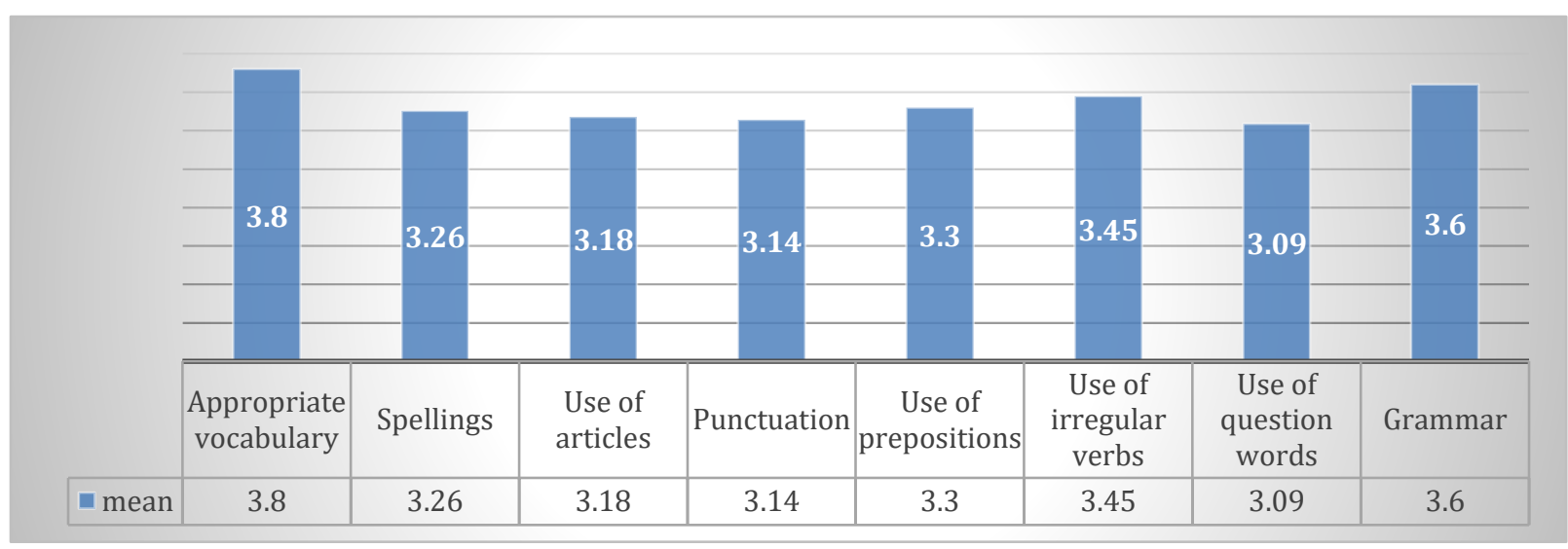

Figure 2. Problems faced in academic writing tasks as perceived by teacher 
Table three indicates that the insufficient number of language courses, few opportunities to use English outside the university and insufficient audio-visual facilities in the classrooms were regarded as three top causes of poor academic writing skills by the participants. However, standard deviation among all eight factors was not significant, implying that participants, by and large, attributed students' poor performance to all of the factors equally. Other obstructive factors included low English language proficiency, teachers' lack of interest in writing tasks, insufficient writing practice, inappropriate teaching methods and insufficient use of dictionaries.

Table 3. Reasons for poor academic writing skills

\begin{tabular}{lllll}
\hline $\mathrm{n}$ & Item & mean & SD & $\begin{array}{c}\mathrm{R} \\
\mathrm{an} \\
\mathrm{N}\end{array}$ \\
& & & & 7 \\
\hline 1 & Low English language proficiency & 3.8 & 1.15 & 7 \\
\hline 2 & Insufficient number of language courses & 4.69 & .56 & 1 \\
\hline 3 & Teachers' lack of interest in writing tasks & 3.74 & 1.07 & 6 \\
\hline 4 & Few opportunities to use English outside the university & 4.61 & .80 & 2 \\
\hline 5 & Inappropriate teaching methods & 4.06 & 1.09 & 5 \\
\hline 6 & Insufficient writing practice & 4.08 & 1.087 & 4 \\
\hline 7 & Insufficient audio-visual facilities in the classrooms & 4.24 & 1.08 & 3 \\
\hline 8 & Insufficient use of dictionaries & 3.72 & 1.07 & 8 \\
\hline
\end{tabular}

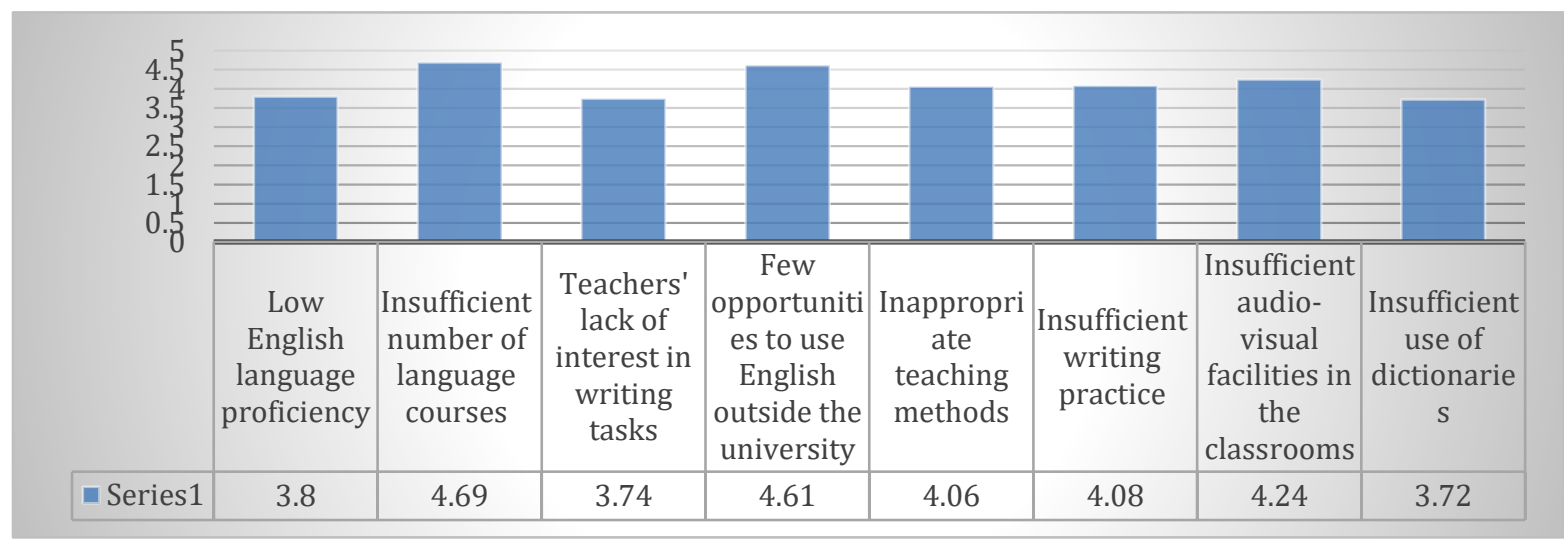

Figure 3. Reasons for poor academic writing skills

Writing has a special role in the academic world globally. Educational institutions try to train students to write competently as writing skills will be essential to their success and will help them to be able to analyse, exchange ideas and think critically and objectively. In higher education in particular, writing can be more difficult for students due to complex subjects that require equally complex language. As a thinking tool, writing can be used for language development and for testing one's language skills. The results of the present study suggest that inadequate English resources and insufficient teaching methods are, in general, the main causes of poor writing skills. The data show the main reasons for this situation among Saudi learners are attributed more to external factors, i.e. institutional policies, faculties and the predominant culture, than internal causes, students' own accountability for their learning, with the latter having significantly lower average values (Al-Saleh, 2018 Alhujaylan, 2019; Khan \& Khan, 2016; Al-Mudhi, 2019; Tanrıkulu, 2020). 
Students in Saudi Arabian schools still shun and/or postpone writing. Most find learning writing a difficult task that needs a lot of time and work. Writing, in a sense, is a laborious activity in that various subcomponents need to be integrated for it to work. There are also individual issues such as dyslexia or dysgraphia, among others. Teachers believe students grapple with the slower, more detailed form of written correspondence due to the faster and predominantly visual input they are exposed and accustomed to on a daily basis on social media and in contemporary lifestyle in general. Students also "can't write" because sometimes the teaching methodology is not efficient and motivating. An efficient approach, and its concomitant methods and techniques, try to present writing as a positive and fulfilling activity where poor performance is addressed and resolved in a friendly but professional manner. Unmotivated students can hardly learn anything, especially when that "thing" is an essential and demanding skill in the calibre of writing. As students are at present largely comprised of the so-called "millennials" and "Generation Z" (or Zoomers), enhanced automation infrastructure can be introduced to improve students' overall digital learning using the tools they are used to and are welcomed by them (Al-Ahdal, et al, 2014; Alfallaj and Al-Ahdal, 2017; Pimada, et al, 2020; Valizadeh and Soltanpour, 2020).

This study considers writing as an essential capacity that enables students to use and learn a new language in a coherent and communicative context and is also a means to clearly and effectively communicate emotions, concepts and feelings (Al-Ahdal \& Alqasham, 2020; Keller, et al., 2020; Landicho, 2020; Uludag, et al, 2019). Teaching it, however, is one of the biggest challenges faced by any educational body worldwide. Writing requires three stages: pre-write, write and post-write (Alkhudiry, Al-Ahdal, \& Alkhudiry, 2020; Magulod, 2018; McDonough \& De Vleeschauwer, 2019; Payant, et al, 2019). In the prewriting phase, students gather data and outline the content, whether it is writing a story, a survey, a letter or a paragraph. Writing paragraphs in particular, is a basic skill needed by educational institutions. A paragraph consists of three main parts: a topic, details and a conclusion and can be written for the purposes of narration, information, recapitulation, reporting, argumentation and description. In the writing phase, they form their drafts into the written text and in the post-writing process, they collaborate with their teacher to improve the quality of the written piece. In the second half of the twentieth century, there were improvements in the teaching of English writing: until the seventies, writing was treated as a product, then as a process and finally as a means for students to learn while writing. Writing now is intended to help students effectively learn, which means they are supposed to practice writing until they are qualified at advanced levels.

\section{Conclusion}

The study set out to investigate the perceptions of tertiary level EFL teachers to the teaching of writing since it is recognized that though writing is a primary skill for higher education, it is also one largely ignored in Saudi tertiary level institutions. Leaners' motivation and teachers' attitudes to the learning and teaching respectively can be decisive in determining the achievement of class objectives, and hence their evaluation needs to be given primacy. The results of this study, despite the relatively low number of participants surveyed (which can be considered one of its limitations), provide valuable insight into the challenges faced by Saudi EFL students in their academic writing. Responses from participants indicate that graduates of major English universities usually do not find it necessary to practice composing different types of essays, for which the instructor is advised to offer students sufficient time and rigorous 
attention. This empirical study also found that Saudi students' inability to compose and commit academic errors was mainly due to lexical aspects, irregular sentences, and orthography.

\section{Implications to Teaching}

Given the poor attendance rate of Saudi students in EFL writing classes in universities and colleges, it seems inevitable to modify the present institutionalized teaching practices and mindsets to address and overcome this unfortunate state. Recent studies point to a rising tendency among Saudi teachers to embrace newer, more 'unconventional' teaching approaches that allow for the incorporation of new and innovative teaching strategies, to inspire students to take up an active role in their classroom activities and their learning in general. It is equally important to equip classrooms with the requisite infrastructure, e.g. audio-visual devices that help with presentation tasks among others. To identify those with more severe writing problems, an assessment test must be administered to students entering colleges, to tailor the content to their needs. Despite universal access to digital online resources, for both teachers and students, faculty members are advised to consult proper dictionaries to ensure that the quality and correctness of speech is observed and restored. Teachers should also inform students about the aims of teaching the particular course and writing at large.

The current study stresses the importance of introducing a new approach to teaching writing skills as current practices do not meet students' needs and do not help them improve and elevate their writing competency. As mentioned earlier in passing, a limitation of this research was the relatively low number of respondents considering it was intended to address a national problem. This was due to a shortage of time and the consequent restraint of meeting deadlines. The study focussed on writing; in the future, similar diagnostic research can be carried out regarding other language skills of speaking, listening and reading.

\section{Acknowledgment}

This research was supported by the Deanship of Scientific Research, Imam Mohammad Ibn Saud Islamic University, Saudi Arabia, Grant No. (19-12-07-004).

\section{About the authors}

Khaled Abkar Alkodimi is an assistant professor of English Language \& Literature, Imam University, Saudi Arabia. He got his PhD. from University Putra Malaysia (UPM) in 2011. Dr. Alkodimi has participated in a number of international conferences and published a number of articles in different internationally scientific indexed journals on a wide range of topics.

ORCID ID: https://orcid.org/0000-0003-4894-8223

Arif Ahmed M. H. Al-Ahdal is a Professor of Applied Linguistics, College of Sciences and Arts, Methnab, Qassim University, Saudi Arabia. Though his vocation is teaching, Dr. Al-Ahdal is an avid poet and writer. He has already published over 30 research papers published in Internationally Scientific Indexed Journals.

ORCID ID: https://orcid.org/0000-0002-6747-0897 


\section{References}

Abedi, P., Namaziandost, E., \& Akbari, S. (2019). The impact of flipped classroom instruction on Iranian upper-intermediate EFL learners' writing skill. English Literature and Language Review, 5(9), 164-172.

Al-Ahdal, A. A. M. H., \& Alqasham, F. H. (2020). Saudi EFL learning and assessment in times of Covid-19: crisis and beyond. Asian EFL Journal, 27(3/4), 356-383.

Al-Ahdal, A. A. M. H. (2020a). Code mixing in Arabic conversations of college students: A sociolinguistic study of attitudes to switching to English. The Asian ESP Journal, 16 (1), 6-19.

Al-Ahdal, A. A. M. H. (2020b). Translanguagism and the bilingual EFL learner of Saudi Arabia: exploring new vistas. Asian EFL Journal, 27(1), 14-26.

Al-Ahdal, A. A. M. H., \& Al-Mashaqba, N. J. H. (2016). English for non-teaching staffers of Qassim University, KSA: The need of the hour. British Journal of English Linguistics, 4(2), 1-25.

Al-Ahdal, A. A. M. H., Alfallaj, F., Al-Awaied, S., \& Al-Hattami, A. (2014). A comparative study of proficiency in speaking and writing among EFL learners in Saudi Arabia. American International Journal of Contemporary Research, 4(2), 141-149.

Alfallaj, F. S. S., \& Al-Ahdal, A. A. M. H. (2017). Authentic assessment: evaluating the Saudi EFL tertiary examination system. Theory and Practice in Language Studies, 7(8), 597607. http://dx.doi.org/10.17507/tpls.0708.01

Alhujaylan, H. (2019). An assessment of the effectiveness of CALL in teaching English Language writing skills in Saudi Arabia. Arab World English Journal (AWEJ) Special Issue on CALL, (5). https://dx.doi.org/10.2139/ssrn.3431731

Alkhudiry, R. I., Al-Ahdal, A. A. M. H. (2020). Analysing EFL discourse of Saudi EFL learners: identifying mother tongue interference. The Asian ESP Journal, 16(2/1), 89-109.

Al-Mudhi, M. A. (2019). Evaluating Saudi university students' English writing skills using analytic ratingscale . Journal of Applied Linguistics and Language Research, 6(4), 95109

Al-Saleh, N. A. (2018). The impact of positive and corrective feedback via Showbie on Saudi students' English writing, (Published Master's Thesis). Imam Muhammad Ibn Saud Islamic University, KSA. DOI: https://dx.doi.org/10.24093/awej/th.215

Bandura, A. (1993). Perceived self-efficacy in cognitive development and functioning. Educational Psychologist, 28(2),117-148. https://doi.org/10.1207/s15326985ep2802_3

Bracewell, R. J. (2020). Investigating the control of writing skills. In reading empirical research studies: The Rhetoric of Research (pp. 436-463). New York: Routledge.

Butler, D. B., Trosclair, E., Zhou, Y., \& Wei, M. (2014). Student and teacher perceptions of academic English writing in Russia. Journal of Teaching English for Specific and Academic Purposes, 2(2), 203-227.

Darmawangsa, D., Mutiarsih, Y., Karimah, I. S., \& Racmadhany, A. (2020, December). Think, talk, and write strategy in French writing skill learning. In 4th International Conference on Language, Literature, Culture, and Education (ICOLLITE 2020) (pp. 143-148). Atlantis Press.

El Tantawi, M., Sadaf, S., \& AlHumaid, J. (2018). Using gamification to develop academic writing skills in dental undergraduate students. European Journal of Dental Education, 22(1), 15-22. https://doi.org/10.1111/eje.12238 
Ferede, T., Melese, E., \& Tefera, E. (2012). A descriptive survey on teachers' perception of EFL writing and their practice of teaching writing: preparatory schools in Jimma zone in focus. Ethiopian Journal of Education and Science. 8(1): 29-52.

Flower, L. and Hayes, J.R. (1981) A cognitive process theory of writing. college composition and communication, 32, 365-387. http://dx.doi.org/10.2307/356600.

Fu, D., \& Matoush, M. (2012). Teachers' perceptions of English language writing instruction in China. International Advances in Writing Research: Cultures, Places, Measures, 23-39.

Go Silk, B. et al (2020). Cognition toward the mother tongue, attitude toward English, Chavacano, and Filipino: A structural equation modeling approach with bootstrap analysis. Asian ESP, 16(1/2), 5-28. https://ssrn.com/abstract=3570991

Hayes, J. R., \& Flower, L. (1981). Uncovering cognitive processes in writing: an introduction to protocol analysis. ERIC Clearinghouse.

Hedge. T. (1988). Writing. Oxford: Oxford University Press.

Hidayati, K. H. (2018). Teaching writing to EFL learners: an investigation of challenges confronted by Indonesian teachers. Langkawi: Journal of The Association for Arabic and English, 4(1), 21-31. http://dx.doi.org/10.31332/lkw.v4i1.772

Hodges, T. S. (2017). Theoretically speaking: an examination of four theories and how they support writing in the classroom. The Clearing House: A Journal of Educational Strategies. 90(4):193-146.

Imsa-ard, P. (2020). Being an effective writing teacher: understanding writing theories behind the product, process, and genre approaches. International Journal of Linguistics and Translation Studies, 1(2), 35-47. https://doi.org/10.36892/ijlts.v1i2.31

Kardena, A., Syarif, H., \& Zaim, M. (2020, December). Analysis of students' point of view regarding to writing skill at English education section of IAIN Bukittinggi. In 2nd International Conference Innovation in Education (ICoIE 2020) (pp. 62-67). Atlantis Press. https://dx.doi.org/10.2991/assehr.k.201209.193

Keller, S. D., Fleckenstein, J., Krüger, M., Köller, O., \& Rupp, A. A. (2020). English writing skills of students in upper secondary education: results from an empirical study in Switzerland and Germany. Journal of Second Language Writing, 48. https://doi.org/10.1016/j.jslw.2019.100700 .

Khan, S. R., \& Khan, M. R. (2016). Error analysis in English writing. International Multidisciplinary Research Journal, 4(2), 232-243.

Kim, Y., \& Kang, S. (2020). Writing to make meaning through collaborative multimodal composing among Korean EFL learners: writing processes, writing quality and student perception. Computers and Composition, 58, https://doi.org/10.1016/j.compcom.2020.102609

Landicho, C. J. B. (2020). Secondary school students' attitudes and practices toward research writing and reporting in science. Issues in Educational Research, 30(1), 156.

Lee, I. (2020). Utility of focused/comprehensive written corrective feedback research for authentic L2 writing classrooms. Journal of Second Language Writing, 49, https://doi.org/10.1016/j.jslw.2020.100734

Listyani, (2018). Enhancing academic writing skills through "reading to learn" strategy. Arab World English Journal, 9(1), 268-280. https://dx.doi.org/10.24093/awej/vol9no1.19

Magulod, G. C. (2018). Use of innovative prewriting techniques in enhancing the writing performance and attitude of second year information technology students. Asia Pacific Journal of Multidisciplinary Research, 6(2), 1-9. 
McDonough, K., \& De Vleeschauwer, J. (2019). Comparing the effect of collaborative and individual prewriting on EFL learners' writing development. Journal of Second Language Writing, 44, 123-130. https://doi.org/10.1016/j.jslw.2019.04.003

McMaster, K. L. et al. (2019). Supporting teachers' use of data-based instruction to improve students' early writing skills. Journal of Educational Psychology.

Oppenheimer, D., Zaromb, F., Pomerantz, J. R., Williams, J. C., \& Park, Y. S. (2017). Improvement of writing skills during college: A multi-year cross-sectional and longitudinal study of undergraduate writing performance. Assessing Writing, 32, 12-27.

Payant, C., McDonough, K., Uludag, P., \& Lindberg, R. (2019). Predicting integrated writing task performance: source comprehension, prewriting planning, and individual differences. Journal of English for Academic Purposes, 40, 87-97.

Pimada, L. H., Toba, R., \& Rasyidi, A. W. (2020). Learning of imla' using flashcards on writing skill at islamic elementary school level in samarinda.izdihar: Journal of Arabic Language Teaching, Linguistics, and Literature, 3(1), 1-16.

Raimes, A. (1983). Anguish as a second language? remedies for composition teachers. in En J. ringle, I. Yalden \& Y. A. Freedman (Eds.), learning to write: first language/second language, (252-272), New York: Longman.

Rakedzon, T., \& Baram-Tsabari, A. (2017). To make a long story short: a rubric for assessing graduate students' academic and popular science writing skills. Assessing Writing, 32, 28-42. https://doi.org/10.1016/j.asw.2016.12.004

Seçer, S. Y. E., \& Yücel-Toy, B. (2020). Impact of writing course design based on 5E learning model on writing skill instruction and development. International Online Journal of Education and Teaching, 7(3),

760-783. https://iojet.org/index.php/IOJET/article/view/841

Sukmawati, N. N., \& Nasution, S. S. (2020). Genre-based approach: can it improve the informatics engineering students' writing skill? JEES: Journal of English Educators Society, 5(1), 95-102.

Surya, A., et al., (2020). Improving high school and vocational school teachers in writing skill. Jurnal Dedikasi, 17(1), 64-71. : https://doi.org/10.22219/dedikasi.v17i1.12021

Tanrikulu, F. (2020). Students' perceptions about the effects of collaborative digital storytelling on writing skills. Computer Assisted Language Learning, 1-16. https://doi.org/10.1080/09588221.2020.1774611

Thonus, T. (2020). The disciplinary identity of second language writing. Journal of Second Language Writing, 49, https://doi.org/10.1016/j.jslw.2020.100725 .

Timizar-Le Pen, T., Marchand, C., Léocadie, M., \& Rothan-Tondeur, M. (2020). Reflective writing: implementation and learning perception from students and teachers of French nursing schools. Nurse Education in Practice, 49, https://doi.org/10.1016/j.nepr.2020.102921 .

Uludag, P., Lindberg, R., McDonough, K., \& Payant, C. (2019). Exploring L2 writers' sourcetext use in an integrated writing assessment. Journal of Second Language Writing, 46, https://doi.org/10.1016/j.jslw.2019.100670

Valizadeh, M., \& Soltanpour, F. (2020). The flipped pedagogy: effects on the grammatical competence and writing skill of basic users of English. International Journal of Instruction, 13(3), 761-776. https://doi.org/10.29333/iji.2020.13351a

Vygotsky, L. (1978). Interaction between learning and development. Readings on the development of children, 23(3), 34-41. 
Zahroh, R., Mujiyanto, J., \& Saleh, M. (2020). Students' attitudes toward teachers' written corrective feedback and their writing skill. English Education Journal, 10(1), 9-17. https://doi.org/10.15294/eej.v10i1.32511

Zemni, B. \& Alrefaee, Y. (2020). Investigating the source of reading anxiety among undergraduate Saudi female EFL students in translation departments. TESOL International Journal, 15 (5), 65-77.

\section{Appendix 1 \\ Questionnaire}

1. What is your opinion about writing as a skill in the EFL classroom and the current tasks and activities?

2. Can you list five reasons why you think writing is important in EFL classes?

3. What is required in the writing for your students to pass their English exam?

4. In your classes, what is the nature of the 'text' that your students are required to produce?

5. To what extent do you think students' assumptions of the difficulty of writing in the foreign language is responsible for the fact that they find English writing tasks difficult?

6. What are the difficulties you, as the teacher, typically face while writing in English?

7. When you assign a writing task, do you work with your student by, for example, helping them revise and edit their work?

8. Is collaboration favoured by your students when they are asked to write?

9. Do you administer techniques such as peer correction or self-correction of the written work?

10. Do you assign writing tasks separately or are they integrated with other skills and tasks?

11. Can you list five causes that in your opinion stymie EFL learners' efforts to improve their writing skills? 